\title{
PRIMARY ACTINOMYCOSIS OF BREAST IN POST MENOPAUSAL WOMAN: A
} CASE REPORT

\author{
Deepak R. Chavan¹, Girish Kullolli2, B. B. Metan³, Anita P. Javalgi ${ }^{4}$
}

\section{HOW TO CITE THIS ARTICLE:}

Deepak R. Chavan, Girish Kullolli, B. B. Metan, Anita P. Javalgi. "Primary Actinomycosis of Breast in PostMenopausal Woman: A Case Report". Journal of Evolution of Medical and Dental Sciences 2014; Vol. 3, Issue 19, May 12; Page: 5279-5282, DOI: $10.14260 /$ jemds/2014/2588

\begin{abstract}
Actinomycosis of breast is a rare disease; only 20 cases have been reported. But majority are secondary in presentation. But this study represents the rarest report of primary actinomycosis in postmenopausal woman in India and in the world. A 55 year old presented with a lump, clinically simulating malignancy, in the right breast. Fine needle aspiration was inconclusive. Mammography showed features of malignancy. Modified radical mastectomy was done, histological diagnosis of ACTINOMYCOSIS was made, rare interesting case discussed.
\end{abstract}

KEYWORDS: Actinomycosis of breast.

INTRODUCTION: Primary actinomycosis of the breast is a rare disease, with fewer than 20 cases reported since its first description by Ammentorp in 1893.1,2 Breast actinomycosis is primary when inoculation occurs through the nipple. Secondary actinomycosis of the breast refers to the extension of a pulmonary infection through the thoracic cage in a process that can affect the ribs, muscles, and finally, the breast. Distinguishing actinomycosis from more common breast lesions such as inflammatory carcinoma is difficult. Gogas et al. ${ }^{3}$ reported that the diagnosis is frequently made after surgery.

This study is the first to include mammographic findings of a patient with primary actinomycosis of the breast. In our study, mammography was not suggestive of actinomycosis. After surgery histopathology report confirmed it as actinomycosis. In this study we want to state that this condition be considered in the differential diagnosis of intractable breast abscess and malignancy to avoid unnecessary major surgery.

CASE REPORT: A 55yr old post-menopausal female patient was admitted on 07/02/10 with complaints of swelling in the right breast since 3 months, Complains of dull aching pain at the lump site.

On examination left side breast normal. Right side fullness present in the middle and outer quadrant, the nipple inverted and areola distorted on right side. Globular lump measuring about $4 \times 5 \mathrm{~cm}$ palpable in the retroaeriolar and upper outer quadrant of the right breast. The skin is pinchable (free from the lump).The lump is fixed to the breast tissue and moves with the tissue, No edema, no discharge, no chest wall fixity.

There was 2 palpable lymph node in the right axilla, provisional diagnosis of Carcinoma breast was made stage 2 (T2 N1 M0). FNAC-showed inflammatory changes. Mammography (fig. 1, 2), showed Large irregular homogenous opacity in the retroareolar region and the right upper and outer quadrant with nipple retraction and skin thickening of the right breast, features suggestive of malignancy. Modified Radical Mastectomy was done. Histopathology of specimen showed Features of actinomycosis with multiple micro abscesses. (fig. 3) 
An uncommon situation of primary actinomycosis of the breast is reported in a 55-year-old woman who presented with a lump, clinically simulating malignancy, in the right breast. Diagnosis of actinomycosis was could have been established by incision biopsy. Resolution of infection, while conserving the breast, may had been achieved by timely diagnosis, limited surgery, and effective antibiotic therapy.

Diagnostic failures leading to avoidable mastectomies have not been uncommon in cases previously reported in the literature. It is, therefore, imperative that this condition be considered in the differential diagnosis of intractable breast abscess and malignancy.

DISCUSSION: Actinomycosis is caused by gram-positive anaerobic filamentous bacteria that are part of the normal oral flora. ${ }^{2,3}$ The most frequent cause is A. israelii, present in $78 \%$ of patients. ${ }^{4}$

Usually, actinomycosis represents a chronic infection characterized by pus, fibrosis, and fistulas that drain sulfur granules. These sulfur granules seen macroscopically represent bacterial colonies that appear microscopically as intertwined radiating filaments ("rays") terminating in pearshaped "clubs." These bacterial colonies may be visualized with Grocott-Gomori coloration. ${ }^{5}$

The main clinical forms of actinomycosis are cervicofacial, thoracic, abdominal, and, in women, pelvic. Dissemination to other organs may occur by spatial contiguity. The disease is four times more common in men; usually the patients are in otherwise good health, with no associated diseases. ${ }^{1}$

Primary actinomycosis of the breast starts at the nipple; most of the abscesses are retropapillary. ${ }^{1}$ Possible causes of this condition observed by Cope and quoted by Lloyd-Davies ${ }^{1}$ include trauma, lactation, and kissing. All reported cases of actinomycosis of the breast have involved premenopausal women. This study represents the first case report of primary actinomycosis of the breast in a postmenopausal woman.

Actinomycosis of the breast usually presents as a recurrent abscess, often retropapillary. Fistulas and purulent or bloody discharge from sinuses may occur. In the most advanced cases of long duration, fibrosis with local cicatrization and architectural distortion of the breast tissue are present. ${ }^{1}$ Moreover, dissemination to other organs may occur. Another possible clinical presentation is a chronic abscess of the breast that Lloyd-Davies. ${ }^{1}$

States is almost impossible to distinguish from inflammatory carcinoma. According to Jain et al. 6 Primary actinomycosis must be considered in the differential diagnosis of chronic breast abscess and malignancy, especially when fine-needle aspiration cytology of apparently malignant masses suggests chronic inflammation.

The diagnosis is made by pathologic examination of the biopsy or mastectomy specimen, in which we can see the characteristic sulfur granules representing the bacterial colonies.

\section{REFERENCES:}

1. Lloyd-Davies JA. Primary actinomycosis of the breast. Br J Surg 1951; 38: 378 -381[Medline]

2. Apothéloz C, Regamey C. Disseminated infection due to Actinomyces meyeri: case report and review. Clin Infect Dis 1996; 22: 621 -625[Medline]

3. Weese WC, Smith IM. A study of 57 cases of actinomycosis over a 36-year period: a diagnostic "failure" with good prognosis after treatment. Arch Intern Med 1975; 135: 1562 -1568 [Abstract] 


\section{CASE REPORT}

4. Lerner PI. Actinomicose. In: Harrison TR, ed. Medicina interna. Rio de Janeiro: McGraw-Hill, 1995; $732-735$.

5. Hennrikus EF, Pederson L. Disseminated actinomycosis. West J Med 1987; 147: 201-204 [Medline].

6. Jain BK, Sehgal VN, Jagdish S, Ratnakar C, Smile SR. Primary actinomycosis of the breast: a clinical review and a case report. J Dermatol 1994; 21: 497 -500 [Medline].

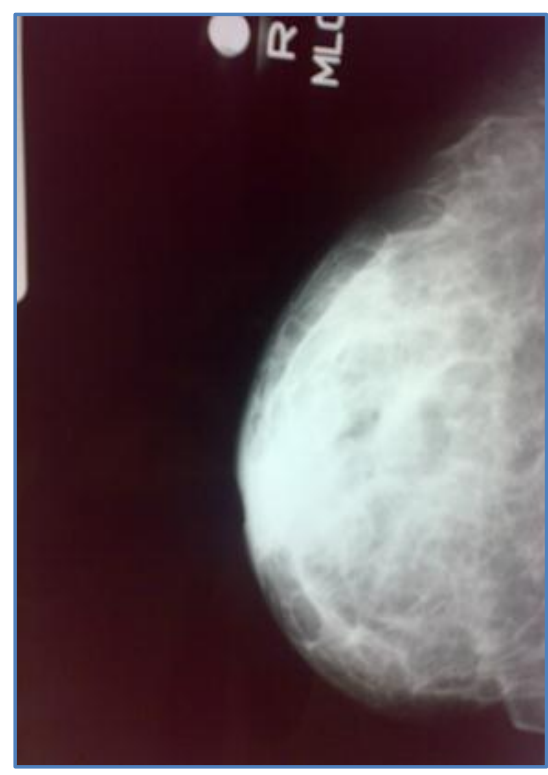

Figure 1

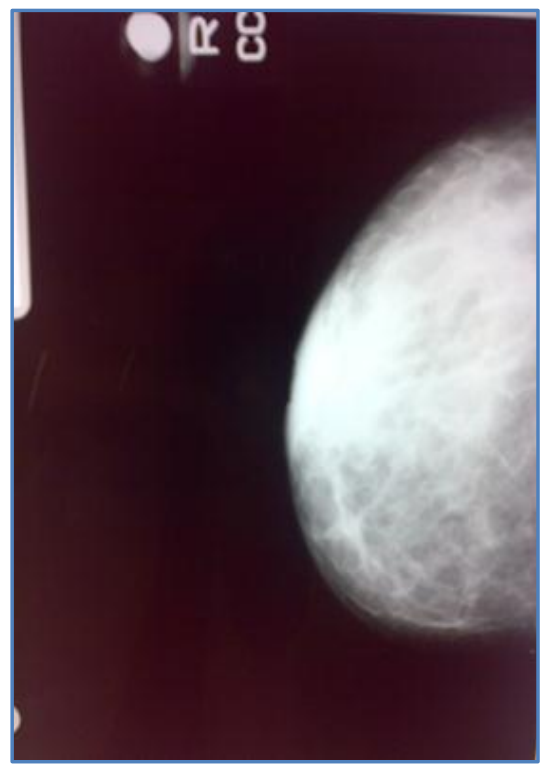

Figure 2: MAMMOGRAPHY FILMS

Fig. 3: histopathologic specimen shows filamentous branching bacteria (arrows) positive to silver impregnation, characteristic of grains of Actinomyces israelii.

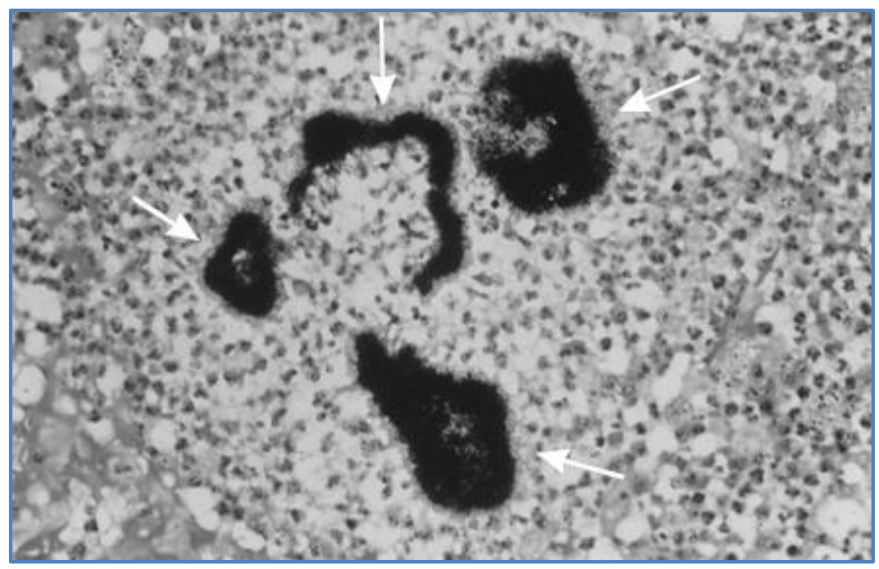

Figure 3 


\section{CASE REPORT}

\section{AUTHORS:}

1. Deepak R. Chavan

2. Girish Kullolli

3. B. B. Metan

4. Anita P. Javalgi

\section{PARTICULARS OF CONTRIBUTORS:}

1. Assistant Professor, Department of Surgery, BLDE University Shri B. M. Patil Medical College, Bijapur, Karnataka India.

2. Assistant Professor, Department of Surgery, BLDE University Shri B. M. Patil Medical College, Bijapur, Karnataka India.

3. Professor, Department of Surgery, BLDE University Shri B. M. Patil Medical College, Bijapur, Karnataka India.
4. Assistant Professor, Department of Pathology, BLDE University Shri B. M. Patil Medical College, Bijapur, Karnataka India.

\section{NAME ADDRESS EMAIL ID OF THE CORRESPONDING AUTHOR:}

Dr. Deepak R. Chavan,

Pragatinagar Ashram Road,

Near Water Tank,

Bijapur-586103,

Karnataka.

Email: dipdeepak@yahoo.co.in

Date of Submission: 24/04/2014.

Date of Peer Review: 25/04/2014.

Date of Acceptance: 03/05/2014.

Date of Publishing: 12/05/2014. 